\title{
MEDIA PEMBELAJARAN QAWAID NAHWU BERBASIS MULTI MEDIA
}

\author{
Nahdiyatul Ummah, M.Pd.I \\ almasalfin@gmail.com
}

\begin{abstract}
Abstrak
Media pembelajaran menjadi penyalur dalam menyampaikan pesan atau materi, media sangat baik dan membantu peserta didik untuk memahami, mengingat serta mencerna mata pelajaran, di era globalisasi ini media merupakan tuntunan dan salah satu media yang paling baik adalah media berbasis multimedia karena memberi rangsangan melalui berbagai alat indra, media ini berdasarkan kemampuan dan kelebuhannya bisa menajadi solusi dalam pembelajaran qawaid nahwu.
\end{abstract}

Keyword: Media Pembelajaran, Qawaid Nahwu, Multimedia

\section{A. Pendahuluan}

Peminat orang yang mau belajar qawaid nahwu semakin hari semakin berkurang seiring dengan majunya peradaban pendidikan serta semakin berkembangnya sistem belajar dan pembelajaran khususnya dibidang bahasa Arab, hal tersebut terjadi karena kebanyakan peminat bahasa Arab dibidang muhadatsah (dialog) tidak memperhatikan qawaid nahwu yang dianggap sulit dan menghambat kelancaran berbahsa umumnya bagi pemula.

Pembelajaran qawaid nahwu banyak ditinggalkan oleh peminat bahasa Arab lantaran beberapa faktor diantaranya pembelajaran qawaid nahwu dengan sistem lama yang kurang efektif, seiring kemajuan pembelajaran saat ini dan kemajuan teknologi yang menjadi media pembelajaran bisa mengembalikan minat peserta didik minat untuk belajar qawaid nahwu.

Pembelajaran qawaid nahwu berbasis multimedia mungkin jarang kita kenal namun ini menjadi solusi yang sangat baik mengingat kemajuan teknologi yang sudah sangat mutahir saat ini dan bisa menjadikan pembelajaran qawaid nahwu lebih efektif dan efisien.

\section{B. Kajian Teori}

Metode gramatika dan terjemah adalah sebuah metode pembelajaran bahasa Arab yang dalam prosesnya mengajarkan kaidah-kaidah tata bahasa dan kosa kata untuk memahami teks berbahasa Arab. Dalam aplikasinya metode ini menggunakan bahasa peserta didik sebagai bahasa pengantar, misalnya bila metode ini diterapkan di di 
sebuah sekolah yang peserta didiknya orang Indonesia maka bahasa pengantar yang digunakan oleh guru dalam mengajarkan bahasa Arab adalah bahasa Indonesia.

Metode ini dianggap sebagai metode tertua dalam pembelajaran bahasa Arab dan dianggap mampu mengembalikan masa kebangkitan negara-negara Islam, karena menyalin peninggalan peradaban manusia dari bahasa-bahasa Yunani dan Latin ke dalam bahasa Arab. Metode yang digunakan dalam pembelajaran bahasa Arab ini adalah menjelaskan kaidah untuk mengajarkan kepiawaian berbahasa Arab tertentu melalui membaca dan menerjemah kemudian pembelajaran kaidah nahwu menjadi tujuan akhirnya, karena ia dianggap sebagai sarana untuk mengembangkan kemampuan berfikir. Metode ini bertujuan untuk mengajarkan kaidah bahasa peserta didik dan bahasa Arab kepada para peserta didik. ${ }^{1}$

Metode nahwu dan terjemah adalah teknik pembelajaran bahasa yang mengacu pada beberapa hal diantaranya menganalisa kaidah nahwu secara terpisah kemudian mempraktekkannya, mengacu pada dua skill yaitu membaca dan menulis, kosakata sesuai dengan teks bacaan, menitik beratkan untuk menerjemahkan kalimat-kalimat berbahasa Arab, mengajarkan tata kalimat dengan metode deduktif dan bahasa peserta didik adalah pengantar yang dipakai guru. ${ }^{2}$

Di era globalisasi dengan semakin pesatnya kemajuan IT juga memberi dampak yang positif seiring berkembangnya pendidikan, banyak media pembelajaran yang menawarkan cara pembelajaran yang lebih efisien dan efektif untuk mencapai tujuan pendidikan dan juga berpengaruh untuk memahami pelajaran bagi peserta didik dilain itu mempermudah guru untuk menyampaikan materi yang sedang disampaikan, media mempunyai banyak manfaat dalam proses pembelajaran. Pertama, pemahaman pengajar terhadap media pembelajaran, adalah: (1) media pembelajaran sebagai alat bantu untuk menyampaikan materi (2) sebagai alat komunikasi untuk merangsang pembelajar belajar, (3) media pembelajaran dapat digunakan untuk menggantikan objek asli yang dipelajari, (4) medai pembelajaran sebagai alat bantu untuk mendukung pembelajaran yang efektif dan efisien untuk mencapai tujuan (5) media sifatnya praktis (6) meningkatkan variasi belajar. ${ }^{3}$

\footnotetext{
${ }^{1}$ Fathur rahman, Metodologi Pembelajaran Bahasa Arab, (Malang: Madani Media, 2015) hlm 135.

2 Ibid, hlm 140-141.

${ }^{3}$ Hujair AH Sanaky, Media Pembelajaran Interaktif-inovatif, (Yogyakarta: KAUKABA DIPANTARA, 2013) hlm 35.
} 
Media adalah sebuah alat yang mempunyai fungsi menyampaikan pesan (Bovee, 1997) Media pembelajaran adalah sebuah alat yang berfungsi dan dapat digunakan untuk menyampaikan pesan pembelajaran. Pembelajaran adalah proses komunikasi antara pembelajar pengajar dan bahan ajar. ${ }^{4}$

Salah satu faktor yang bisa mempengaruhi proses pembelajaran berjalan dengan baik, efektif dan efisien ialah pemilihan media yang sesuai dengan kebutuhan materi yang disampaikan agar dapat diterima dengan baik serta peranan teknologi yang bisa mendukung media untuk diaplikasikan dan dapat merangsang proses belajar mengajar dengan baik.

Perubahan teknologi yang saat ini terjadi dan akan terus berlanjut sepanjang sejarah manusia harus kita tanggapi dengan baik guna memahami fenomena tersebut jika ingin maju secara profesional untuk mendukung proses belajar siswa. ${ }^{5}$ media baru merupakan istilah umum yang digunakan untuk menggambarkan teknologi akhir abad ke-20 dan itu yang baru. Hal baru ini tidak terbatas pada internet, telepon seluler, televisi interaktif, permainan di komputer dan dunia virtual. ${ }^{6}$

Komputer adalah alat elektronik yang termasuk pada kategori multimedia, karena komputer menurut Arsyad mampu melibatkan berbagai indera dan organ tubuh, seperti telinga (audio) mata (visual) dan tangan (kinetik) yang dengan pelibatan ini dimungkinkan informasi atau pesannya mudah dimengerti. ${ }^{7}$

Pemanfaatan multimedia berbasis komputer yang dapat digunakan dalam proses pembelajaran meliputi:

\section{Multimedia Presentasi}

Multimedia presentasi digunakan untuk menjelaskan materi-materi yang sifatnya teoritis digunakan dalam pembelajaran klasik, baik untuk kelompok kecil maupun besar. Media ini cukup efektif sebab menggunakan multimedia projector (LCD/Viewer) yang memiliki jangkauan pancar yang cukup besar, multimedia dalam presentasi ini biasanya menggunakan power point. ${ }^{8}$

\section{Program Media Interaktif}

\footnotetext{
4 Ibid, hlm 3.

${ }^{5}$ Marc Prensky dkk, Educational Technology for School Leaders, (California: Corwin 2012) hlm 88.

${ }^{6}$ Ibid, hlm 90.

${ }^{7}$ Yudhi Munadi, Media Pembelajaran: Sebuah Pendekatan Baru, (Jakarta Selatan: Referensi, 2013) hlm 148.

8 Ibid, hlm 150.
} 
Secara teknis media pembelajaran berfungsi sebagai sumber belajar yang dipahami sebagai segala macam sumber yang ada diluar diri seseorang (peserta didik) yang memungkinkan terjadinya proses belajar baik secara individual maupun kelompok dengan artian dalam beberapa hal media pembelajaran dapat menggantikan fungsi guru terutama sebagai sumber belajar, multimedia interaktif dapat digunakan dalam kegiatan pembelajaran sebab cukup efektif meningkatkan hasil belajar peserta didik. ${ }^{9}$

Komputer sebagai salah satu merupakan salah satu bentuk media pembelajaran berupa perangkat keras (hardware) . Keberadaan komputer bisa menjadi alat bantu belajar sekaligus bisa menjadi sumber belajar yang bisa membantu guru dan siswa dalam menyalurkan dan menerima materi pembelajaran agar lebih optimal.

Dengan mengfungsikan perangkat yang ada dalam jaringan komputer pembelajaran akan menjadi lebih efektif dan efisien. Sebab komputer bisa menampilkan pesan secara visual, audio, bahkan audio visual. Dengan berinteraksi langsung siswa bisa menggunakan komputer sebagai sumber informasi pembelajaran.

Multifungsi komputer tersebut akhirnya pembelajaran pun banyak yang menggunakan komputer sebagai alat bantu sekaligus sumber informasi. Pembelajaran dengan menggunakan komputer dikenal dengan konsep pembelajaran dengan bantuan komputer (komputer-assisted Intruction). Dalam konsep CAI ini komputer difungsikan sebagai penyaji materi pembelajaran, penyimpan materi pelajaran, hingga pembelajaran berbasis komputer.

Sedangkan bentuk pembelajarannya bisa berbentuk tutorial, drills and practice, simulasi, dan permainan. Saat ini juga telah berkembang software dan hardware yang digunakan dalam pembelajaran berbasis komputer.

Pembelajaran berbasis komputer berarti proses pembelajaran yang menggunakan alat bantu dan sumber belajar dengan sistem komputer atau berbasis mikro prosesor dalam mencapai tujuan pembelajaran. Media pembelajaran berbasis komputer sangat diperlukan sebab media komputer memiliki karakteristik yang mudah difahami dan digunakan dalam pembelajaran. Teknologi tinggi yang berbasis komputer dan televisi memberi keluasan anak didik untuk mengadopsi pengetahuan dari media tersebut yang dapat mendukung pembelajaran di kelas (Joyce, $1999: 6) .{ }^{10}$

\footnotetext{
9 Ibid, hlm 151-152.

${ }^{10}$ Musfiqon, Pengembangan Media dan Sumber Pembelajaran, (Jakarta: PT. Prestasi Pustakarya, 2012) hlm 190.
} 


\section{Kesimpulan}

1. Metode gramatika dan terjemah adalah sebuah metode pembelajaran bahasa Arab yang dalam prosesnya mengajarkan kaidah-kaidah tata bahasa dan kosa kata untuk memahami teks berbahasa Arab

2. Komputer adalah alat elektronik yang termasuk pada kategori multimedia, karena komputer menurut Arsyad mampu melibatkan berbagai indera dan organ tubuh, seperti telinga (audio) mata (visual) dan tangan (kinetik) yang dengan pelibatan ini dimungkinkan informasi atau pesannya mudah dimengerti

\section{Kritik dan Saran}

\section{Daftar Pustaka}

Rahman, Fathur, Metodologi Pembelajaran Bahasa Arab, Malang: Madani Media, 2015.

Sanaky, Hujair AH, Media Pembelajaran Interaktif-inovatif, Yogyakarta: KAUKABA DIPANTARA, 2013.

Prensky, Marc, dkk, Educational Technology for School Leaders, California: Corwin 2012.

Munadi, Yudhi, Media Pembelajaran: Sebuah Pendekatan Baru, Jakarta Selatan: Referensi, 2013.

Musfiqon, Pengembangan Media dan Sumber Pembelajaran,Jakarta: PT. Prestasi Pustakarya, 2012. 